\title{
EFECTOS DE LA CONCILIACIÓN EXTRAJUDICIAL EN DERECHO EN LOS PROCESOS DE RESTITUCIÓN DE BIEN INMUEBLE ARRENDADO ORIGINADOS EN CONTRATOS CELEBRADOS DE FORMA VERBAL, AÑO 2017
}

\author{
Nubia Elena Valdelamar Támara ${ }^{1}$ \\ Elida Rosa Parra Castro ${ }^{2}$ \\ José Pablo Arrieta Oviedo 3
}

\section{Resumen}

A partir de la celebración de contratos de arrendamiento, surge el proceso de restitución de bien inmueble arrendado como acción que tiene el arrendador para recuperar la tenencia del bien. Paralelamente a la existencia del proceso en mención, existe la posibilidad de celebrar audiencias de conciliación para hacer cumplir obligaciones establecidas en la celebración del contrato pero que en el desarrollo del mismo son incumplidas por alguna de las partes. En el presente capitulo encontramos un rastreo normativo acerca de la conciliación extrajudicial en derecho como requisito de procedibilidad en los procesos de naturaleza civil, el contrato de arrendamiento y los procesos de restitución de inmueble arrendado enfatizando en los

$1 \quad$ Especialista en Derecho Procesal Civil. Coordinadora del Centro de Conciliación del Consultorio Jurídico de la Facultad de Derecho y Ciencias Políticas de la Corporación Universitaria del Caribe "CECAR". Abogada y Conciliadora en Derecho, Email: nubia.valdelamart@cecar.edu.co

2 Abogada. Diplomado en Conciliación y Solución de Conflictos (En curso). Auxiliar Consultorio Jurídico y Centro de Conciliación de la Facultad de Derecho y Ciencias Políticas de la Corporación Universitaria del Caribe "CECAR". Email: elida.parra@cecar. edu.co

3 Egresado del programa de Derecho. Diplomado en Conciliación y Solución de Conflictos (En curso). Especialización en Derechos Humanos y Justicia Transicional (En curso). Monitor del Consultorio Jurídico adscrito al Centro de Conciliación del Consultorio Jurídico de la Facultad de Derecho y Ciencias Políticas de la Corporación Universitaria del Caribe "CECAR". Email: jose.arrietao@cecar.edu.co 
casos en que se ha celebrado mediante contrato verbal, un cuadro normativo sobre la conciliación en materia civil, un flujograma sobre el contrato de arrendamiento y el proceso de Restitución de inmueble arrendado, incluyendo el trámite conciliatorio y un análisis de las estadísticas del Centro de Conciliación de la Corporación Universitaria del Caribe CECAR, durante el año 2017 en relación a las solicitudes y resultados obtenidos en los procesos de restitución de bien inmueble arrendado haciendo mayor énfasis en aquellos que se celebraron de forma verbal y se ha logrado esteblecer que la efectividad de la aplicación de la conciliación a este tipo de procesos es notoria desde la citación a la audiencia de conciliación a la parte citada, ya que, en algunas situaciones, como se pudo corroborar a través del seguimiento, el arrendatario obtiene la restitución del bien inmueble simplemente con la presentación de la citación, llegando a un consenso extrajudicial sin necesidad de celebrar audiencia de conciliación.

Palabras clave: Conciliación, Contrato de arrendamiento, Restitución inmueble arrendado

\section{Abstract}

From the conclusion of lease contracts, the process of restitution of leased property arises as an action that the lessor has to recover the tenure of the property. Parallel to the existence of the process in question, there is the possibility of holding conciliation hearings to enforce obligations established in the conclusion of the contract but that in the development of the same are breached by one of the parties. In this chapter we find a normative trace on the extrajudicial conciliation in law as a procedural requirement in civil proceedings, the lease contract and the processes of restitution of leased property emphasizing in cases where it has been entered into by verbal contract, a normative framework on conciliation in civil matters, a flowchart on the lease contract and the process of restitution of leased property, including the conciliation process and an analysis of the statistics of the Conciliation Center of the Corporación Universitaria del Caribe CECAR, The effectiveness of the application of conciliation to this type of proceedings is evident from the summons to the conciliation hearing to the cited party, since in some situations, as could be corroborated through follow-up, the tenant obtains restitution of the 
real estate simply by filing the summons, reaching an extrajudicial consensus without the need to hold a conciliation hearing

Keywords: Conciliation, Lease agreement, Restitution of leased property.

\section{Introducción}

El presente trabajo de investigación se desarrolla a partir de la figura jurídica denominada proceso de restitución de bien inmueble arrendado, la cual se encuentra consagrada en el Código General del Proceso y que tiene sus inicios en el acuerdo de voluntades de las personas que suscriben contratos de arrendamiento de vivienda urbana, los cuales, como lo estipula la ley, pueden celebrarse de forma verbal o escrita. A partir de esta figura, existe la posibilidad de celebrar audiencias de conciliación cuando el contrato es celebrado de forma verbal para hacer cumplir obligaciones que se pactaron al inicio del mismo pero que en el desarrollo del acuerdo son incumplidas por alguna de las partes.

Desde el Centro de Conciliación del Consultorio Jurídico de la Corporación Universitaria del Caribe - CECAR se ha podido evidenciar que uno de los asuntos más comunes tratados en materia civil es la restitución de bien inmueble arrendado. Igualmente, se ha notado que de los usuarios que solicitan audiencias de conciliación para este asunto, existe un porcentaje que no celebró el contrato de arrendamiento por escrito sino de manera verbal, razón por la que acuden al centro de conciliación para lograr la restitución del bien sin necesidad de llegar a una instancia judicial, previendo los inconvenientes que puede implicar el no tener un contrato por escrito que demuestre la existencia del negocio jurídico, presentándose casos en que sin ser necesaria la conciliación como requisito de procedibilidad es utilizada, como por ejemplo cuando la causal es mora en el pago de lo cánones.

Por otra parte, se ha podido identificar que en la mayoría de las solicitudes de audiencia de conciliación que tiene por objeto la restitución de bien inmueble arrendado, tanto cuando se tiene un contrato escrito como uno verbal, existen pretensiones adicionales tales como el pago de cánones atrasados, el pago de servicios públicos domiciliarios adeudados, entre otras; es decir, que los usuarios no solo están utilizando los servicios del centro para obtener una pronta restitución del bien, sino también para satisfacer otras pretensiones de carácter económico que en la administración de justicia demandarían un tiempo más extenso y un desgaste del aparato jurisdiccional. 
Conforme a todo lo anteriormente planteado, se hace necesario determinar ¿Cuáles son los efectos de la conciliación extrajudicial en derecho en los procesos de restitución de bien inmueble arrendado originados en contratos celebrados de forma verbal a partir del análisis del Centro de Conciliación del Consultorio Jurídico de la Corporación Universitaria del Caribe - CECAR durante el año 2017? Para dar respuesta al interrogante anteriormente planteado, el objetivo general de la investigación es determinar cuáles son los efectos de la conciliación extrajudicial en derecho en los procesos de restitución de bien inmueble arrendado originados en contratos celebrados de forma verbal a partir del análisis del Centro de Conciliación del Consultorio Jurídico de la Corporación Universitaria del Caribe - CECAR durante el año 2017. El cual será desarrollado a través del cumplimiento de los siguientes objetivos específicos:

- Conceptualizar la conciliación extrajudicial en derecho como requisito de procedibilidad en los procesos de naturaleza civil conforme a la legislación colombiana.

- Describir el proceso de restitución de bien inmueble arrendado desde un estudio normativo enfatizando en los casos en los cuales encuentra su origen en un contrato verbal y los efectos de la conciliación extrajudicial en derecho en este tipo de procesos.

- Analizar las estadísticas del Centro de Conciliación del Consultorio Jurídico de la Corporación Universitaria del Caribe - CECAR en relación a los procesos de restitución de inmueble arrendado celebrados bajo la modalidad de contrato verbal.

Esta investigación es de gran relevancia, pertinencia e impacto puesto que sus resultados nos permitirán tener claridad frente a la efectividad del servicio que se presta a diario en el Centro de Conciliación de CECAR en el área civil, específicamente en los procesos de restitución de bien inmueble arrendado, que de ahora en adelante se denominarán RBIA, originados a partir de la celebración de un contrato verbal. Así mismo, a través del cumplimiento de los objetivos específicos de la presente investigación se podrá establecer la efectividad de los seguimientos que se realizan con posterioridad a la celebración de la audiencia.

Del mismo modo, la presente investigación será de gran utilidad y desarrollo para, la sociedad, el Centro de Conciliación y para los presentes 
investigadores. Será de utilidad para la sociedad porque en la medida en que se socialicen los resultados de la investigación se dará a conocer la importancia de suscribir contratos por escrito al momento de celebrar negocios de arrendamiento de bienes inmuebles, a su vez, será útil en la medida en que nos permitirá dar a conocer la conciliación como un mecanismo de solución de conflictos del cual disponen las personas para zanjar sus diferencias y al que pueden acceder de manera gratuita si se utilizan los servicios del Centro de Conciliación de CECAR.

En cuanto a la utilidad que representará la investigación para el Centro de Conciliación del Consultorio Jurídico de CECAR, se puede decir que se logrará determinar el aporte del centro a la descongestión de los despachos judiciales del distrito judicial en el que tiene incidencia el consultorio jurídico. Igualmente, el desarrollo de la investigación permitirá evaluar el desempeño del Centro de Conciliación en cuanto al cumplimiento de las actas de conciliación expedidas en la materia objeto de estudio. También, será útil puesto que dentro de sus resultados se dejará un instrumento consistente en un flujograma que permitirá analizar más fácilmente la efectividad del centro en los procesos de RBIA y que podrá ser utilizada para el análisis de investigaciones de los años posteriores.

Por otra parte, en lo atinente a la utilidad para los investigadores, el desarrollo de la presente investigación implicará un crecimiento en el ámbito profesional y académico, puesto que nos permitirá adquirir nuevas competencias en materia de investigación, la cual en el área jurídica cada día se está convirtiendo en un factor importante para el ejercicio de la profesión y para continuar la formación posgradual, además porque permitirá afianzar los conocimientos adquiridos con respecto a la conciliación extrajudicial en derecho como mecanismo alternativo de solución de conflictos, el contrato de arrendamiento de vivienda urbana y el proceso de restitución de bien inmueble arrendado.

\section{Metodología}

La presente investigación es de carácter cualitativo con un nivel hermenéutico. Este tipo de investigación constituye un multimétodo focalizado, teniendo en cuenta la interpretación y aproximaciones naturalistas a su objeto de estudio (Denzin, 2012). La investigación es de tipo cualitativa porque se pretende describir cuales son los efectos de la conciliación extrajudicial en derecho en los procesos RBIA originados en 
Efectos de la conciliación extrajudicial en derecho en los procesos de restitución de bien inmueble arrendado originados...

un contrato verbal, asimismo, para darle cumplimiento al objetivo general, se realizará un análisis estadístico a través del cual determinaremos cuantas audiencias de conciliación referentes a la materia objeto de investigación fueron celebradas en el Centro de Conciliación del consultorio jurídico de CECAR en el año 2017. La investigación tiene un nivel hermenéutico que se justifica en el análisis normativo y estadístico de los casos de RBIA atendidos y desarrollados por los estudiantes del centro de conciliación en sus prácticas jurídicas.

Por otro lado, la presente investigación es netamente jurídica con un enfoque epistemológico. Es jurídica porque las fuentes principales objeto de análisis son normatividades que rigen la conciliación extrajudicial en derecho (Ley 640 de 2001 y demás normatividad relacionada), el contrato de arrendamiento de vivienda urbana (Ley 820 de 2003) y el proceso de restitución de bien inmueble arrendado (Código General del Proceso), así mismo, tiene un enfoque epistemológico porque se realizará un análisis estadístico a partir de datos existentes en el archivo del Centro de Conciliación de CECAR.

Para alcanzar cada uno de los objetivos específicos de la presente propuesta se seguirá una secuencia de actividades divididas en tres fases:

FASE 1: Para el cumplimiento del primer objetivo se llevará a cabo un rastreo normativo y bibliográfico acerca de la conciliación extrajudicial en derecho como requisito de procedibilidad para los procesos de naturaleza civil. Igualmente, se elaborará un marco normativo sobre la materia.

FASE 2: Para alcanzar el segundo objetivo propuesto se hará un rastreo normativo y bibliográfico respecto al proceso de restitución de bien inmueble arrendado. Del mismo modo, se elaborará un marco normativo y doctrinal acerca de este tema, haciendo énfasis en los casos en que el contrato de arrendamiento se celebra de forma verbal.

FASE 3: Finalmente para lograr el tercer objetivo, se llevarán a cabo varias actividades como lo son la revisión de las estadísticas propias del centro de conciliación del consultorio jurídico de CECAR para el año 2017 en cuanto a las audiencias programadas referentes a la materia estudiada y la revisión de los seguimientos preexistentes con relación a dichas audiencias. Lo anterior se documentará teniendo en cuenta varios aspectos como el número de audiencias programadas sobre RBIA con contrato escrito y con contrato verbal, número de audiencias en las cuales además se solicitó pago de cánones, pago de servicios públicos domiciliarios y otras pretensiones adicionales, resultados de las audiencias programadas (acuerdo total, 
acuerdo parcial, no acuerdo, inasistencia de una parte, inasistencia de ambas partes, fijación de nueva fecha y retiro de la solicitud) y cumplimientos o incumplimientos de los acuerdos logrados.

Dentro de las fuentes primarias que se utilizan en el desarrollo de la investigación se encuentran las estadísticas propias del Centro de Conciliación del Consultorio Jurídico de CECAR y los seguimientos existentes de cada una de las audiencias de conciliación celebradas en relación al asunto objeto de estudio.

En cuanto a las fuentes secundarias a utilizar, se tendrán en cuenta libros, capítulos de libro, trabajos de grado y demás producciones bibliográficas referentes al tema estudiado. También se usará el marco normativo existente en la materia.

\section{Marco referencial}

\section{Marco histórico}

El conflicto es una condición inherente al hombre que ha estado presente desde el origen de la humanidad, en ese sentido, sería desacertado plantear que las formas de resolver conflictos tienen un origen definido e intentar encontrar dicho origen en un punto específico de la historia. Desde una perspectiva histórica, sería difícil determinar si apareció primero la autocomposición o la heterocomposición como manera de resolver conflictos (Diaz \& Contreras, 2010). Sin embargo, se puede decir tal como lo manifiesta Varón (2002), que la intervención no decisoria de terceros en la resolución de conflictos (autocomposición) es una práctica tan antigua como la humanidad, esta ha evolucionado hasta llegar a lo que hoy son los diferentes mecanismos alternativos de solución de conflictos (MASC).

En Colombia, gracias a la jurisprudencia de la Corte Suprema de Justicia (1948), contamos con una ilustración de la evolución histórica que ha tenido la conciliación hasta llegar a como se encuentra regulada hoy en día. En ese sentido, se puede evidenciar que la conciliación tiene antecedentes verificables que van desde Roma, Grecia, China, Japón y África.

En Roma, por ejemplo, la Ley de las XII es un antecedente de la conciliación en tanto que en una parte establece que lo que convinieran las partes al ir al juicio tenía fuerza vinculante, igualmente, el contrato de transacción que gozaba de bastante aplicación en Roma es un antecedente de la conciliación porque, tal como lo mencionaba Cicerón, 
Efectos de la conciliación extrajudicial en derecho en los procesos de restitución de bien inmueble arrendado originados...

al sacrificar algo del propio derecho de los litigantes, esta podía ser más ventajosa que un pleito, ya que había que alejarse de estos (Instituto SER, 1996).

En Grecia, en el periodo clásico (499 a.C. - 323 a.C.) existían personas con competencia atribuida para examinar las causas determinantes de un litigio y procurar el acercamiento entre las partes para lograr una transacción entre estas que pusiera fin al conflicto, a esto se le llamo tesmotetes. Por su parte en China, tal como menciona Confucio, los conflictos se resolvían a través de la persuasión moral y el acuerdo, y no bajo coacción, por lo cual la mediación era el principal mecanismo para dirimir las diferencias, rechazando los recursos adversariales que afectarían las relaciones armoniosas (Folberg \& Taylor, 1997).

En Japón, existían la conciliación y la mediación en cabeza de un líder que tenía el deber de brindar ayuda a las personas de la población para solucionar sus discrepancias. Asimismo, en África, estas eran solucionadas informalmente con una junta de vecinos, gracias a la que una persona respetada buscaba acercar a las personas en disputa para que lograran solucionar su problemática.

En la religión, siempre se han interpretado los pleitos como el resultado de las pasiones humanas, y en ese sentido, siempre se ha incentivado la resolución pacífica de los conflictos. En esa medida, en los siglos VII a XII, los procesos eclesiásticos decretaban intentar la reconciliación entre las personas previo a una decisión judicial, siendo, sin embargo, una figura facultativa y no un presupuesto obligatorio.

De acuerdo a lo anterior, conociendo que la conciliación y, en general, los mecanismos auto compositivos de resolución de conflictos, tienen antecedentes remotos en todas las civilizaciones, es preciso decir que, pese a que esta existía y era reconocida, no en todos los países era entendida de la misma manera, por lo cual se evidencia, por ejemplo, que en países como Francia, España, Italia y Alemania, se instituyera la conciliación como obligatoria antes de acudir a un proceso judicial; mientras que en otros países no lo fue, debido a que consideraban que el hecho de que la conciliación fuera impuesta como un requisito previo, la convertía en un mero trámite, un pasaporte para acceder a la justicia al que las partes acudían sin ningún ánimo conciliatorio.

En Colombia, la Conciliación como mecanismo alternativo de resolución de conflictos puede decirse que surge en el año 1825, desde la expedición de la Ley 13 en la que se estableció la obligatoriedad 
de intentar la Conciliación antes de darle trámite a cualquier proceso contencioso civil. Desde dicha ley hasta la actualidad se ha dado una evolución normativa la cual se abordará en el marco normativo de la presente investigación. Por otra parte, teniendo en cuenta el otro eje del presente capítulo, es preciso hacer mención a la evolución histórica del contrato de arrendamiento y del proceso en mención. Conforme a lo anterior, se tiene que el contrato de arredamiento, al igual que muchas de las demás instituciones jurídicas del Derecho privado, tiene su origen en el Derecho romano. El contrato de arrendamiento no aparece como un contrato independiente y autónomo sino como una derivación del contrato de compraventa. En ese sentido, se conoció el contrato de arrendamiento con el nombre de locatio, lo cual significaba locación, alquiler, arriendo.

La locatio se acompañaba de otra palabra dependiendo de a qué hacía referencia dicho alquiler, así pues, estaba el locatio condictio operarum referente al arrendamiento de servicios; el locatio operis, referente al arrendamiento de obra; el locatio conductio piscatus, es decir, arrendamiento de pesca en una zona determinada; el locatio conductio agri vectigalis, que se entendió como el arrendamiento de bienes de corporaciones públicas o tierras del Estado; y finalmente, el locatio conductio rei, referente al arrendamiento de cosas, el cual consistía en la entrega de un determinado bien para el uso y goce al arrendatario y en virtud a dicha entrega, este se obligaba a cancelar una prestación periódica denominada merces (Ardila, 1991).

Teniendo en cuenta la gran influencia del derecho romano para las legislaciones civiles en una gran cantidad de países alrededor del mundo, no es de extrañar que la naturaleza y clasificación del contrato de arrendamiento tal como se reguló en Roma y los mecanismos para su terminación y restitución, se extendería a otros países, es así como en Francia, el Código Francés de 1807 adoptó el criterio del arrendamiento de cosas y de obra, igualmente, el Código civil chileno de 1856 acoge una clasificación aún más fiel a la romana, es decir, el arrendamiento de cosas, de servicios y de obras; esta última clasificación la reproduce el Código Civil Colombiano expedido en 1873. Posteriormente, el arrendamiento de servicios, referido a los criados domésticos y regulado por los artículos 2045 a 2052 del Código Civil colombiano son subrogados por el Código Sustantivo del Trabajo en los artículos referentes al contrato de trabajo. 
Efectos de la conciliación extrajudicial en derecho en los procesos de restitución de bien inmueble arrendado originados...

\section{Marco normativo}

En Colombia, la Conciliación extrajudicial en Derecho, aparece en el ordenamiento jurídico desde el año 1825, con la ley 13 del mismo año promulgada por Francisco de Paula Santander, en la cual se establece por primera vez la conciliación como requisito de procedibilidad en procesos contenciosos civiles para acudir a la jurisdicción ordinaria, siendo los alcaldes municipales o parroquiales las personas facultadas para celebrar esta audiencia y quienes debían procurar porque las partes transigieran los conflictos y se avinieran entre sí en una conciliación amigable (Osorio, 2002).

Respecto a esta primera aparición de la conciliación en la normatividad colombiana es necesario hacer algunos comentarios. En primer lugar, cabe mencionar que no se tiene conocimiento, dado la carencia de documentos históricos, de la efectividad de esta norma en cuanto a la solución de los conflictos, sin embargo, sí se puede considerar que una las razones que pudieron llevar al establecimiento de esta figura en ese momento pudo ser la existencia de un aparato judicial bastante disperso en el territorio y que impedía que cualquier persona accediera fácilmente a este (Restrepo, 2011).

Otra apreciación que se hace de la conciliación tal y como se estableció por primera vez, es la naturaleza jurídica de esta en razón a quien estaba facultado para llevarla a cabo. En ese sentido, al ser celebrada la audiencia por el alcalde del lugar donde ocurrieron los hechos, se tiene que esta conciliación era de naturaleza administrativa y no judicial en cabeza de particulares investidos con facultad de administrar justicia de manera transitoria como lo es en la actualidad (Estrada, 2011).

Otra norma en la cual se vislumbran aspectos relevantes para la conciliación en el ordenamiento jurídico colombiano es en el Código Civil (Ley 84 de 1873), en el cual, varios artículos tales como el 25, el 16 y el 1602 reflejan la posibilidad de los particulares para disponer y por lo tanto renunciar a aquellos derechos que exclusivamente se prediquen de intereses individuales, así como la imposibilidad de renunciar a aquellos derechos que procuran por el orden público (Peña, Polo, \& Solano, s. f.).

Posteriormente, a partir de la ley 120 de 1921, la conciliación tuvo un amplio desarrollo en materia laboral. Es así como gracias a la citada ley, se instituyó la conciliación como facultativa para resolver conflictos en el derecho laboral colectivo, posteriormente, con el decreto 2154 de 1948 se amplía la implementación del mecanismo a conflictos de derecho laboral individual. Hasta este momento, solo era posible la conciliación 
laboral para conflictos jurídicos y con la expedición de los decretos 2663 y 3743 de 1950 que se regula la conciliación para conflictos económicos y de interés. (Osorio, 2002). En el año 1971, con la expedición de Código de Comercio (Decreto 410 De 1971), se le otorgó la facultad a las Cámaras de comercio para resolver las diferencias surgidas entre deudores y acreedores en materia comercial, dando origen a los primeros centros privados de conciliación y de arbitraje (Restrepo, 2011).

Con la expedición del Código de Procedimiento Civil (1970), y la modificación hecha a este por el decreto 2282 en el año 1989, se estableció en el art. 101 la audiencia preliminar, en la cual la primera etapa consistía en intentar la conciliación con el fin de evitar un litigio largo y un mayor desgaste del aparato judicial, esta se instituyó para los procesos declarativos, estableciendo algunas excepciones que por la naturaleza misma del proceso impedían la celebración de la conciliación. La ley 23 de 1991, teniendo en cuenta la necesidad de descongestionar los despachos judiciales y de hacerlos más eficientes, creó la conciliación en equidad y los Centros de Conciliación extrajudicial. Ese mismo año, con la promulgación de la Constitución Política que hoy en día nos rige, de conformidad a lo establecido en la parte final del artículo 116, se le otorga facultad a los particulares para que, de manera transitoria, administren justicia mediante la aplicación de los Mecanismos alternativos de Solución de Conflictos - MASC, dentro de estos la conciliación.

Posterior a la expedición de la Carta Política, surge la Ley 446 de 1998, en esta ley se comenzaron a sistematizar los MASC para que no estuvieran dispersos en la legislación y para armonizar ciertas disposiciones. Esta ley abordó aspectos como la conciliación en el área contencioso-administrativa y de familia, reguló aspectos relacionados a los conciliadores, los centros de conciliación y la conciliación en equidad, además de tocar temas sobre el procedimiento arbitral y regular la figura de la amigable composición, en los artículos 130 a 132. (Silva, 2009). Esta ley fue desarrollada a su vez por el Decreto 1818 de 1998, el cual además realizó una compilación de las normas sobre los MASC para constituir su primer estatuto.

Con relación a la existencia de Centros de Conciliación de las facultades de Derecho del país, fue la resolución 800 de 2000 expedida por el ministerio de justicia y del derecho establece los requisitos para la creación de estos centros de conciliación. Con posterioridad, la Ley 640 de 2001 llega a regular todo lo correspondiente a la conciliación extrajudicial en derecho (deberes de los conciliadores, procedimiento, requisito de 

inmueble arrendado originados...

procedibilidad, documentos, registro, etc.), siendo en la actualidad la principal norma en materia de conciliación como mecanismo alternativo de resolución de conflictos y como estrategia de descongestión judicial. Con posterioridad a esta norma se han expedido otras normas relativas a la conciliación que han depurado este mecanismo en las distintas áreas (Estrada, 2011). Hasta este punto, si bien, no se ha mencionado toda la normatividad que ha existido en Colombia sobre la conciliación, sí se ha hecho un bosquejo que ha permitido verificar como ha sido su evolución en el derecho dentro de nuestro País.

A diferencia de la conciliación, el contrato de arrendamiento de vivienda urbana ha sido normativamente más estable puesto que a lo largo de la historia colombiana ha tenido un número menor de normas las que lo han regulado, siendo las dos más importantes el Código Civil y la ley 820 de 2003. Aunque en Colombia se puede identificar el origen normativo del contrato de arrendamiento antes del Código Civil, para hacer este estudio tendríamos que remitirnos a Las Siete Partidas, la Recopilación de las Leyes de los Reinos de Indias, la Nueva Recopilación y la Novísima Recopilación (Montoya, 2015). Como se ha mencionado anteriormente, el Código Civil expedido en 1873 introduce al ordenamiento jurídico colombiano el contrato de arrendamiento tal como se manejaba en el Derecho Romano, esta regulación se encuentra en el Libro IV del Código, referente a las obligaciones y los contratos, y desde el artículo 1973 regula aspectos como los tipos de arrendamiento, las obligaciones de las partes que cada uno de estos contratos (arrendador y arrendatario), la expiración del contrato concluyendo con una serie de casos o relativos al arrendamiento de bienes diferentes de cosas corporales. Esta regulación incluía normas relativas al arrendamiento d criados domésticos, las cuales, como ya se ha mencionado, fueron subrogadas por el Código Sustantivo (Montoya, 2015).

Posteriormente, Con la expedición del Código de Comercio en 1971, se buscó establecer normas especiales referentes al arrendamiento de inmuebles utilizados para el desarrollo de actividades comerciales en establecimientos de comercio.

En 1985 con la Ley 56, se regularon aspectos relativos al arrendamiento de bienes inmuebles urbanos destinados a vivienda, dentro de los motivos por lo que se proclamó esta norma se encuentra la importancia de tener en cuenta la finalidad social que debe tener la propiedad privada. Esta ley incluía aspectos como una definición del contrato de arrendamiento de vivienda urbana, el termino del 
contrato, la prórroga, el valor del canon de arrendamiento, y su reajuste, las obligaciones del arrendador y del arrendatario, la terminación del contrato, entre otros aspectos. (Pineda \& Resptrepo, 2014).

Actualmente, el contrato de arrendamiento de vivienda urbana es regulado por la ley 820 de 2003, esta ley regula varios aspectos tales como la forma en que se puede celebrar el contrato, las clases, el término de duración, las obligaciones de las partes intervinientes en el negocio jurídico, el procedimiento para el pago por consignación, los servicios públicos domiciliarios, el subarriendo, el valor del canon de arrendamiento, la terminación del contrato, entre otras disposiciones.

Por otra parte, con respecto a la acción procesal que tiene el arrendador para recuperar la posesión del bien que se entrega en arrendamiento, conocido hoy como el proceso de restitución inmueble arrendado (RBIA), este ha evolucionado normativamente a la par de las normas que han regulado el contrato de arrendamiento. De esta manera, tanto el Código Civil, como la Leyes 56 de 1985 y 820 de 2003, establecían en su momento aspectos procesales relativos al contrato de arrendamiento adicionales a las disposiciones que traían los códigos de procedimiento civil.

Inicialmente, el proceso era denominado "Proceso de Lanzamiento de Arrendatario", y se encontraba regulado por el C. de P.C, en su artículo 434, norma que posteriormente fue remplazada por el artículo 424 del C. de P.C. que estableció reglas sobre el mismo proceso, pero cambiándole la denominación a la que conocemos actualmente, la cual es proceso de Restitución de Inmueble Arrendado. En estas regulaciones procesales se establecen aspectos específicos que se aplican de manera adicional a las normas generales de los procesos, como por ejemplo, el tramite preferencial de este tipo de procesos y la única instancia cuando la causal que se alega para obtener la restitución es la mora (Semillero de estudios procesales Escuela de Derecho, 2013).

Actualmente, el proceso de restitución de inmueble arrendado se encuentra regulado por el Código General del Proceso (Ley 1564 de 2012) especialmente por el articulo 384 el cual toca aspectos como los anexos de la demanda, las notificaciones, la contestación, la imposibilidad del demandado de ser escuchado mientras no consigne los cánones dejados de cancelar, los tramites inadmisibles, las medidas cautelares, los casos en que se puede solicitar la restitución provisional y la única instancia cuando la causal es mora. 
Efectos de la conciliación extrajudicial en derecho en los procesos de restitución de bien inmueble arrendado originados...

\section{Marco conceptual}

La conciliación tal como se ha regulado por la normatividad en Colombia es un Mecanismo Alternativo de solución de Conflictos por medio del cual dos o más personas gestionan por sí mismas la solución de sus diferencias con la ayuda de un tercero neutral y calificado llamado conciliador (Ley 446 de 1998.), sin embargo, para tener un concepto más claro de que implica dicha definición es necesario abordar categorías como el conflicto y los MASC.

Conforme a lo anterior, al habar de conflicto, etimológicamente, proviene del latín conflictus que deriva del verbo confligere que significa pelear, combatir, luchar. El diccionario de la Real academia de la lengua española define el conflicto como un problema o cuestión materia de discusión (Real Academia Española, 2001). De acuerdo a estas dos definiciones se puede identificar el factor que permite determina la existencia del conflicto, esto es la existencia de intereses contrapuestos o por lo menos la creencia de que existe una incompatibilidad entre dichos intereses que hacen que dos personas entren en contradicción (Peña O. , 2010).

El conflicto, es una condición connatural al hombre, lo que no es natural es la violencia en la que puede desembocar un conflicto, (Mendoza \& Sánchez, 2016), asimismo, el fracaso en la transformación del conflicto es lo que conduce a la violencia. El conflicto, puede entenderse como un mal o como un motor para el cambio, pero, por ser algo inherente a la sociedad, se puede decir, no es bueno ni es malo, sino que simplemente está presente y que se debe manejarlos de manera que no desemboquen en violencia, ya que los conflictos no se terminan nunca sino solo se resuelven o se solucionan, es decir que se busca ponerlos en un punto en que las tensiones sean tan bajas que sean imperceptibles, estando siempre presente el riesgo de que se reactiven.

Atendiendo a la naturaleza del conflicto, se puede identificar en él varios elementos, como lo son la pluralidad de actores, puesto que siempre se requiere al menos dos personas para que se configure, la incompatibilidad de intereses que genera el conflicto y la interacción que se origina en razón a dicha incompatibilidad y que redunda en la forma en cómo se aborda el conflicto. Igualmente, los conflictos pueden ser violentos o no violentos, verticales cuando son entre desiguales y horizontales cuando son entre iguales. Dentro de las maneras a las que se ha recurrido para resolver los conflictos se han creado los Mecanismos Alternativos de Solución de Conflictos, conocidos con la sigla MASC. 
Los MASC son, en sentido amplio, todos los procedimientos o herramientas que ofrecen la posibilidad de solucionar o resolver los conflictos sin necesidad de acudir a los medios ordinarios u oficiales que no son otros que los procesos judiciales (Peña O. , 2010). Estos mecanismos, la doctrina los ha clasificado en autocompositivos y heterocompositivos, siendo los primeros aquellos en los que las partes toman la decisión de manera directa aun cuando lo hagan con ayuda de un tercero, pudiendo mencionar aquí la transacción, la conciliación y la mediación, y los segundos aquellos en los cuales los individuos ceden la potestad de decidir a un tercero, tales como en el arbitraje y la amigable composición.

A los MASC y dentro de ellos a la conciliación, se les ha atribuido gran importancia desde la jurisprudencia nacional, entre otras razones porque buscan hacer efectiva la convivencia pacífica como uno de los fines esenciales del estado, además, porque le permiten a las personas interesadas poder participar de manera activa en la solución de sus conflictos, también por ser un gran aporte en materia de acceso a la administración de justicia y por ser un medio para lograr la descongestión judicial que es un problema que aqueja al país. (Corte Cnstitucional Colombiana. Sentencia C - 222, 2013).

Por otra parte, al ser considerada la conciliación como un MASC, algunos autores han manifestado la inconformidad con el hecho de que actualmente sea situada como un método alterno o una forma anormal y que se mire al proceso judicial como el canal natural para resolver las diferencias, sin tener en cuenta que incluso desde la historia misma se ha demostrado que la conciliación es la vía natural de arreglar las controversias inherentes ser humano por sus diferencias (Mendoza \& Sánchez, 2016).

Una vez abordado el conflicto y los MASC, es preciso decir que la conciliación es un Mecanismo alternativo de Solución de Conflictos de naturaleza auto compositiva, puesto que, si bien existe la intervención de un tercero denominado conciliador, la decisión final del asunto tratado recae exclusivamente en las partes. Al llegar a un acuerdo gracias a la implementación de este mecanismo se expide un acta que tiene los mismos efectos de una sentencia, pudiendo identificar así que dentro de las ventajas que tiene la conciliación se encuentran el ahorro de tiempo, ahorro de dinero, la voluntariedad y la confidencialidad.

En materia civil, la conciliación implica un debate en el cual las partes se encuentran en igualdad de condiciones, siendo los derechos en juego, por lo general, de naturaleza patrimonial, respecto de los 
que los particulares ejercen su autonomía para disponer de ellos. La autorización de intervención que otorgan las partes al conciliador es transitoria, y se agota cuando éstas firman el acuerdo de conciliación, siendo este acuerdo de carácter permanente y obligando a las partes a su cumplimiento. (Corte Cnstitucional Colombiana. Sentencia C - 222, 2013).

Por su parte, el contrato de arrendamiento, al igual que la conciliación, se encuentra plenamente definido en la ley de manera general como un contrato en el cual las dos partes, establecen obligaciones mutuas en las que se concede el goce de una cosa a cambio de una contraprestación económica (Ley 84 de 1873). Específicamente, el contrato de arrendamiento de vivienda urbana es definido de la misma forma, remplazando el término amplio de cosa por el de inmueble urbano destinado a vivienda (Ley 820 de 2003).

De la definición anteriormente mencionada, se puede determinar que el contrato de arrendamiento de vivienda es un negocio jurídico de carácter bilateral por ser necesaria la existencia del arrendador y del arrendatario; igualmente es oneroso por cuanto implica la existencia de beneficios y cargas para cada una de las partes intervinientes; asimismo, es un contrato conmutativo ya que las obligaciones pactadas son claras y determinadas, no estando supeditadas al azar; además de esto, es de tracto sucesivo puesto que las obligaciones acordadas por las partes se renuevan con el tiempo.

Finalmente, en cuanto al proceso de restitución de inmueble arrendado, este es un proceso declarativo que se puede iniciar ante el aparato judicial con el fin de dar por terminado el contrato de arrendamiento celebrado y recuperar la tenencia del arrendatario sobre el bien cedido en virtud a dicho contrato. Este proceso se encuentra regulado en el Código General del Proceso (Ley 1564 de 2012) dentro de los procesos verbales, con unas reglas específicas establecidas en el artículo 384 y que más adelante serán abordadas. 


\section{Tabla 1}

Normatividad de la conciliación extrajudicial en derecho como requisito de procedibilidad en procesos de naturaleza civil.

\begin{tabular}{|c|c|c|c|}
\hline NORMA & OBJETO & ARTS. & TEMA ABORDADO \\
\hline $\begin{array}{l}\text { Constitución } \\
\text { Política de } \\
\text { Colombia } \\
\text { (1991) }\end{array}$ & $\begin{array}{c}\text { Constitución } \\
\text { Política de } \\
\text { Colombia de } \\
1991 .\end{array}$ & $\begin{array}{c}2,95- \\
6,116 \\
229\end{array}$ & $\begin{array}{l}\text { Fundamento constitucional de } \\
\text { la conciliación y de los MASC en } \\
\text { general: } \\
\text { - Convivencia pacífica como fin } \\
\text { esencial del estado. } \\
\text { - Deber de propender al } \\
\text { mantenimiento de la paz. } \\
\text { - Facultad otorgada a particulares } \\
\text { para administrar justicia de manera } \\
\text { transitoria. } \\
\text { - Derecho de acceso a la } \\
\text { administración de justicia. }\end{array}$ \\
\hline Ley 270 (1996) & $\begin{array}{l}\text { Ley estatuta- } \\
\text { ria de admi- } \\
\text { nistración de } \\
\text { justicia }\end{array}$ & $\begin{array}{c}8,13 \\
-3\end{array}$ & $\begin{array}{l}\text { Fundamento legal de los MASC: } \\
\text { - Se autoriza al legislador a regular } \\
\text { los MASC. } \\
\text { - Se desarrolla la facultad de los } \\
\text { particulares de administrar justicia } \\
\text { transitoriamente a través de la } \\
\text { conciliación y el arbitraje. }\end{array}$ \\
\hline Ley 446 (1998) & $\begin{array}{l}\text { Sobre des- } \\
\text { congestión, } \\
\text { eficiencia y } \\
\text { acceso a la } \\
\text { justicia. }\end{array}$ & 64 & $\begin{array}{l}\text { Se define la conciliación como un } \\
\text { MASC por medio del que dos o más } \\
\text { personas, gestionan por sí mismas, } \\
\text { la resolución de sus desavenencias, } \\
\text { con el apoyo de un tercero neutral } \\
\text { y calificado llamado conciliador. }\end{array}$ \\
\hline
\end{tabular}




\begin{tabular}{|c|c|c|c|}
\hline NORMA & OBJETO & ARTS. & TEMA ABORDADO \\
\hline $\begin{array}{l}\text { Decreto } 1818 \\
\quad(1998)\end{array}$ & $\begin{array}{c}\text { Estatuto } \\
\text { de los } \\
\text { mecanismos } \\
\text { alternativos } \\
\text { de solución } \\
\text { de conflictos. }\end{array}$ & $\begin{array}{l}1,2,3 \\
5,8,9\end{array}$ & $\begin{array}{l}\text { - Se define la conciliación. } \\
\text { - Asuntos conciliables (los que } \\
\text { admitan transacción, desistimiento } \\
\text { y la ley expresamente lo permita). } \\
\text { - Efectos de la conciliación (presta } \\
\text { mérito ejecutivo y hace tránsito a } \\
\text { cosa juzgada). } \\
\text { - En casos de restitución de } \\
\text { inmueble arrendado, si hay } \\
\text { incumplimiento de un acta de } \\
\text { conciliación, se autoriza a los } \\
\text { Centros de Conciliación para que } \\
\text { soliciten al juez que comisione a la } \\
\text { inspección de policía para llevar a } \\
\text { cabo la diligencia de entrega del } \\
\text { bien. } \\
\text { - Se autoriza a las personas } \\
\text { jurídicas privadas sin ánimo de } \\
\text { lucro, a las entidades públicas y } \\
\text { a las facultades de Derecho para } \\
\text { crear centros de conciliación y se } \\
\text { establecen los requisitos. }\end{array}$ \\
\hline Ley 640 (2001) & $\begin{array}{c}\text { Por la cual } \\
\text { se modifican } \\
\text { normas } \\
\text { relativas a la } \\
\text { conciliación } \\
\text { y se dictan } \\
\text { otras } \\
\text { disposiciones }\end{array}$ & $\begin{array}{c}1,2,3 \\
4,5,7 \\
8,10 \\
11,13 \\
18,27 \\
35,38\end{array}$ & $\begin{array}{l}\text { - Normas generales sobre la } \\
\text { conciliación (actas, constancias, } \\
\text { clases de conciliación y gratuidad). } \\
\text { - Normas sobre los conciliadores } \\
\text { (calidades y obligaciones). } \\
\text { - Normas sobre los centros de } \\
\text { conciliación (creación, centros de } \\
\text { consultorios jurídicos facultades } \\
\text { de derecho, obligaciones). }\end{array}$ \\
\hline
\end{tabular}




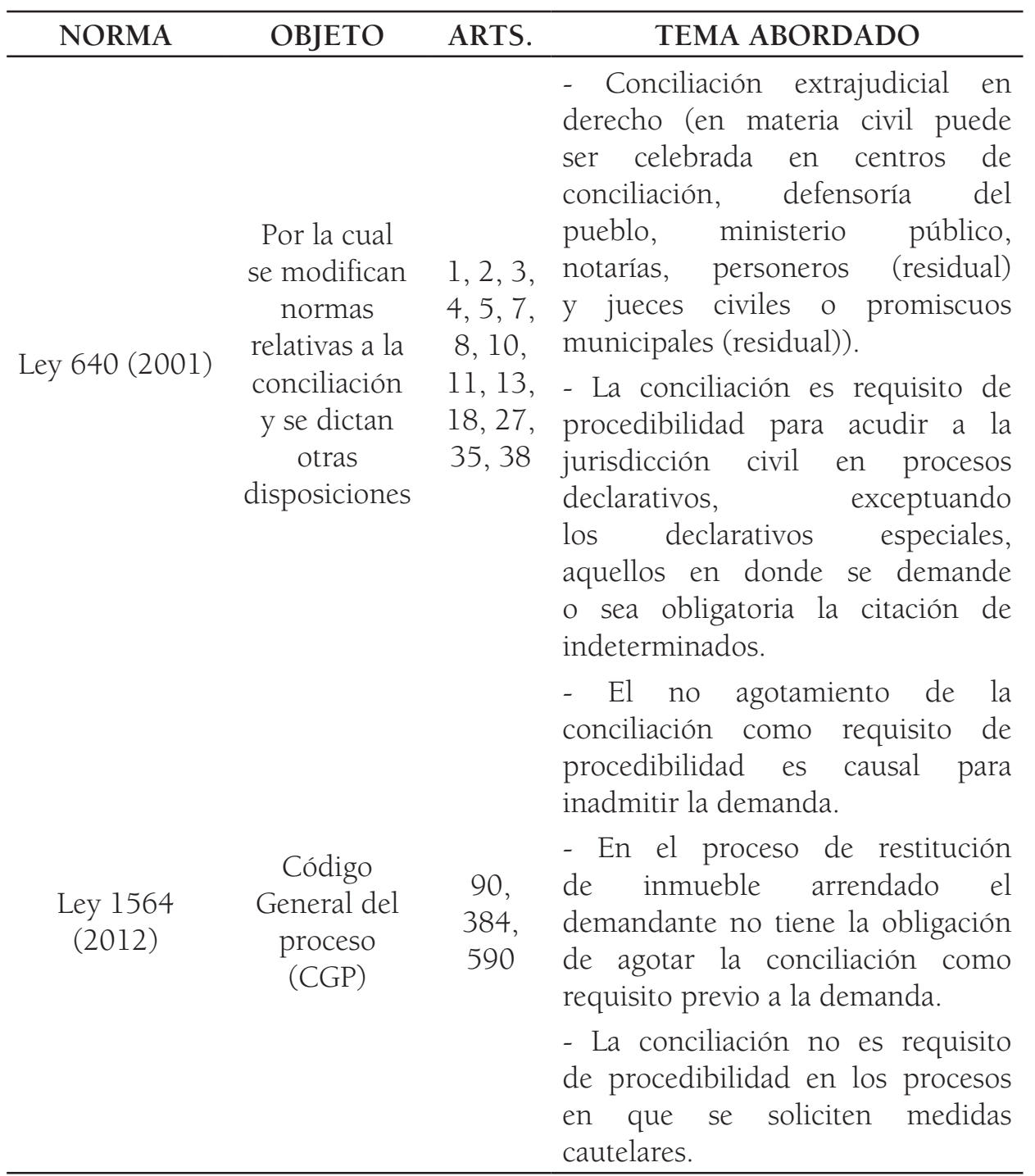

Elaborada por los investigadores en mención, con base en las leyes vigentes sobre Conciliación en materia Civil en Colombia. 

inmueble arrendado originados...

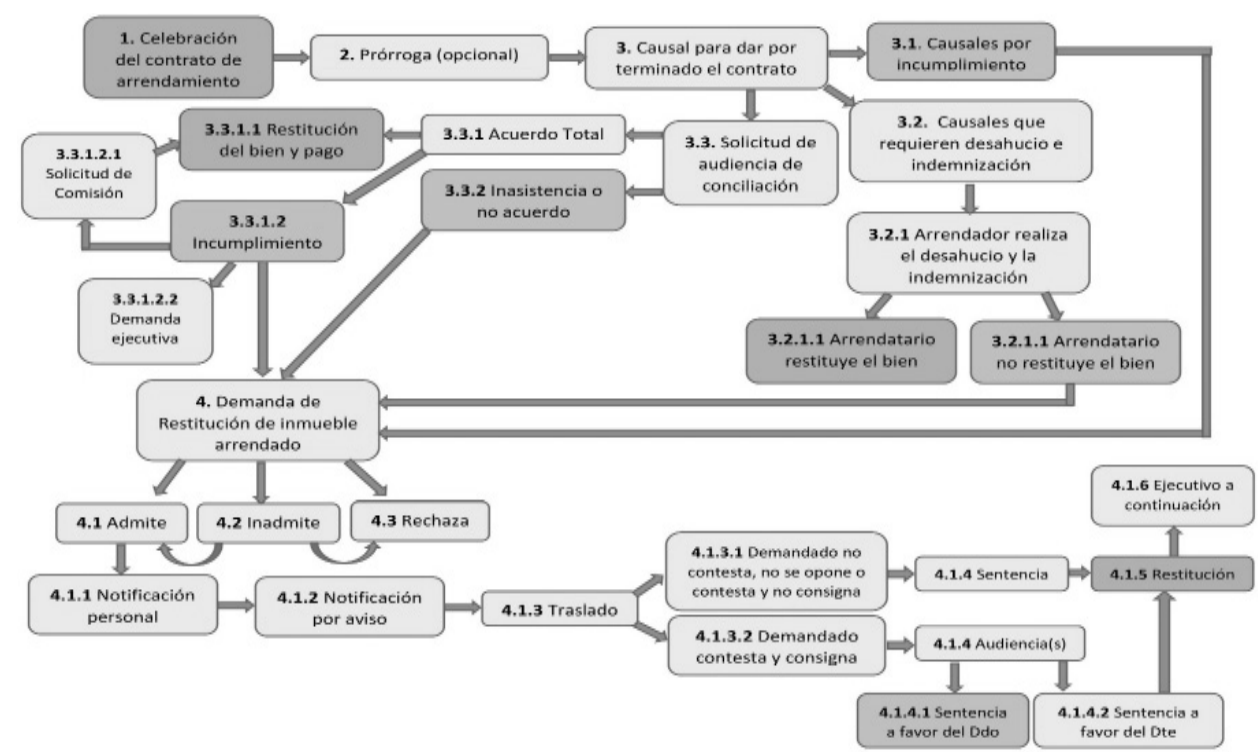

Gráfico 1. Normatividad sobre el proceso de restitución de bien inmueble arrendado

Elaborada por los investigadores en mención, con base en las leyes vigentes sobre Conciliación en materia Civil en Colombia.

En el flujograma anterior se muestran los eventos que se pueden presentar desde la celebración de un contrato de arrendamiento hasta la restitución del bien inmueble arrendado. A continuación, se presenta una explicación detallada del flujograma con anotaciones de la normatividad correspondiente a cada evento posible.

\section{Celebración del contrato de arrendamiento (Ley 820 de 2003):} Es el momento en que las partes (arrendador y arrendatario) acuerdan, bien sea de manera verbal o escrita, que el arrendador cede el uso y goce del bien inmueble urbano destinado para vivienda al arrendatario a cambio de una prestación económica que será cumplida de forma sucesiva de acuerdo a lo convenido por las partes. De la celebración de este contrato se deben identificar los siguientes elementos (Art. 3):

- Identificación de los contratantes y del inmueble sobre el que recae el contrato, o de la parte de este que se arrienda.

- Determinación del valor del canon de arrendamiento y la forma de pago de este.

- Término de duración del contrato, el cual, sino se estipula expresamente, es de un año (Art. 5). 
- Especificación de los servicios con los que se entrega el bien inmueble, tales como energía, agua, gas, alcantarillado, entre otros, y a cargo de quien están. Igualmente, especificación de los servicios conexos o adicionales acordados (internet, televisión, telefonía) y a cargo de quien se encuentran.

2. Prórroga (Ley 820 de 2003): Una vez cumplido el término inicialmente pactado en el contrato de arrendamiento, o cumplido un año si no se estipuló dicho término, si ninguna de las partes del contrato manifiesta la intención de dar por terminado el contrato, este se entenderá prorrogado en las mismas condiciones y por el mismo término inicial, siempre y cuando tanto arrendador como arrendatario hayan dado cumplimiento a cada una de las obligaciones estipuladas y el arrendatario acepte el aumento en el valor del canon efectuado de conformidad a la ley. (Art. 6).

3. Causal para dar por terminado el contrato (Ley 820 de 2003): Dentro del término de duración del contrato, al finalizar dicho término o dentro de una de sus prorrogas, se pueden presentar ciertas situaciones que den pie para que las partes.

3.1. Dentro de las causales mencionadas, existen causales en razón al incumplimiento que permiten que el arrendador inicie de inmediato el proceso de RBIA sin necesidad de realizar el preaviso y la indemnización, dentro de estas causales se encuentran el no pago de los cánones de arrendamiento, la mora en el pago de servicios públicos domiciliarios, el subarriendo por parte del arrendatario sin autorización expresa del arrendador, la perturbación de la tranquilidad de los vecinos o colindantes, la realización de mejoras en el bien sin autorización expresa del propietario (Art. 22 núm. 1-5).

3.2. Adicionalmente, existen causales que requieren el agotamiento por parte del arrendador de un trámite consistente en realizar un preaviso (desahucio) que generalmente debe ser efectuado con al menos tres meses de anticipación y otorgar una indemnización al arrendatario. Dentro de estas causales se pueden mencionar cuando el arrendador requiera el bien para su habitación propia, para remodelaciones o para venta definitiva del inmueble (Art. 22 núm. 7-8). Una vez el arrendador realiza el preaviso y entrega la indemnización conforme al trámite legal (Art. 23) es posible que el arrendatario restituya el bien inmueble, sin embargo, también es posible que el arrendatario no restituya el bien, caso en el cual el arrendador deberá iniciar el proceso judicial de RBIA ante los jueces competentes. 
3.3. En cualquier caso, el arrendador tiene la posibilidad de acudir a la conciliación como mecanismo para obtener la restitución del bien y el pago de cualquier prestación economica que adeude el arrendatario sin necesidad de acudir al aparato judicial, aunque esta no sea requisito de procedibilidad para proceder con la demanda de RBIA. En ese orden de ideas, podría presentar la solicitud de audiencia de conciliación ante cualquier centro de conciliación como es el del consultorio jurídico de CECAR, ante defensoría del pueblo, el ministerio público o notarías, y residualmente ante los personeros o ante los jueces civiles o promiscuos municipales (Ley 640, 2001).

Cuando la solicitud de audiencia de conciliación se realiza ante el Centro de Conciliación del Consultorio Jurídico de CECAR, la cual es totalmente gratuita se procede a verificar que se encuentren los anexos necesarios para agendar y celebrar la audiencia, cuando se trata de contrato de arrendamiento celebrado de forma verbal, se solicita la presentación del documento de identidad, el documento que acredite la propiedad o posesión del bien arrendado (promesa de venta, contrato de compraventa, escritura pública o certificado de tradición y libertad) y el recibo de energía para determinar que de acuerdo al estrato socioeconómico existe competencia por parte del centro. Una vez agendada la audiencia es designada a uno o más conciliadores que son estudiantes de décimo semestre.

De la celebración de la audiencia de conciliación solicitada por el arrendador para lograr la restitución del inmueble arrendado pueden darse varios resultados. De esta manera, de conformidad al artículo 2 de la Ley 640, si la parte citada (arrendatario) no comparece, se expide una Constancia de inasistencia, si ambas partes se presentan a la audiencia, pero no se llega a ningún acuerdo se expide una constancia de no acuerdo (Ley 640, 2001). En ambos casos, el arrendador debe iniciar el proceso de RBIA (3.3.2).

Por otra parte, si en la audiencia de conciliación se llega a un acuerdo total (3.3.1), en el cual se pacta la restitución del bien en determinada fecha y adicionalmente el pago de cualquier prestación económica surgida de la mora en los cánones, en los servicios públicos domiciliarios o por daños causados, por ejemplo, se levanta un acta de conciliación que debe cumplir con los requisitos del artículo 1 de la Ley 640 y que pasa a tener los mismos efectos de una sentencia judicial, esto es, que hace tránsito a cosa juzgada por no poderse volver a tratar el mismo asunto nuevamente y presta mérito ejecutivo en el entendido 
que el incumplimiento de las obligaciones de contenido patrimonial suscritas en el acta por una de las partes dan la posibilidad a la otra de iniciar un proceso ejecutivo obligando a su cumplimiento.

Suscrita el acta, es posible que el citado (arrendatario), a la fecha acordada, restituya el bien y cancele cualquier prestación establecida (3.3.1.1). Siendo también posible que el arrendatario incumpla el acta de conciliación, en este caso, el arrendador tiene tres posibilidades: la primera presentar la demanda de RBIA; la segunda, iniciar el proceso ejecutivo para hacer cumplir la obligación de hacer (restituir el bien) y las obligaciones de dar (pago de sumas de dinero); y en tercer lugar, el Centro de Conciliación puede solicitar al juez para que este comisione a la inspección de policía para celebrar la diligencia del bien tal como lo manifiesta el artículo 5 del Decreto 1818 (1998)

4. Demanda de Restitución de bien inmueble arrendado: Cuando existe una causal de dar por terminado el contrato de arrendamiento en razón al incumplimiento de las obligaciones por parte del arrendatario, cuando el arrendador ha realizado el preaviso correctamente y ha entregado la indemnización, pero el arrendatario se niega a restituir el bien, cuando se cita a audiencia de conciliación y no hay acuerdo o no asiste el citado, el arrendador puede iniciar el proceso de RBIA ante los jueces civiles municipales o jueces civiles del circuito dependiendo de la cuantía del proceso, la cual se determina conforme a las reglas establecidas en el artículo 26 numeral 6 del CPG (Ley 1564 de 2012).

Al momento de presentar la demanda de RBIA, el demandante debe tener en cuenta varias reglas especiales establecidas en el artículo 384 del CGP (Ley 1564 de 2012) que existen para este proceso. En primer lugar, adicional a los requisitos generales de la demanda del artículo 82 del CGP, el demandado debe anexar a la demanda la prueba de la existencia del contrato, la cual, cuando el contrato es de manera verbal se puede constituir por una declaración jurada ante notaria, un interrogatorio extraprocesal de parte o una prueba testimonial sumaria (no controvertida). Igualmente, dependiendo de cada caso en particular, el demandante debe aportar ciertos documentos, como por ejemplo los que acrediten el preaviso la indemnización cuando es el caso.

Una vez presentada la demanda, el juez, después de realizar el respectivo estudio, puede admitirla (4.1), inadmitirla (4.2) o rechazarla (4.3), conforme a las causales establecidas en el artículo 90 del CGP (Ley 1564 de 2012). En ese sentido, para el caso de la inadmisión, si el 
demandante no subsana dentro de los 5 días siguientes, se rechaza la demanda, y si subsana, se admite la demanda.

Al admitir la demanda, el juez reconoce personería jurídica al apoderado del demandante y ordena la notificación al demandado. Esta notificación debe ser realizada por el demandado en los términos de los artículos 291 y 292 del CGP (Ley 1564 de 2012). En ese sentido, inicialmente, se debe remitir por correo certificado al demandado una comunicación en la que se le informe acerca de la existencia del proceso, su naturaleza y la fecha dela auto admisorio, manifestándole además que debe comparecer al juzgado a notificarse personalmente dentro de los 5 días siguientes si reside en el mismo municipio, 10 días siguientes si reside en otro municipio o dentro de los 30 días siguientes si reside en el exterior. Igualmente, según el artículo 384 del Código, para efecto de notificación se considera que la dirección del demandado es la misma del inmueble arrendado.

Si el demandado no comparece al juzgado para notificarse personalmente, el demandante debe efectuar la notificación por aviso, la cual consiste en enviar nuevamente una comunicación por correo certificado al demandado en la que se plasmen los mismos datos de la citación anterior, anexando copia de la demanda y del auto admisorio, manifestando además que la notificación se entenderá surtida al finalizar el día siguiente después de recibida la comunicación, fecha en la que comenzará a correr el término de traslado el cual es de 10 días, dentro de los cuales el demandado puede tomar varias posiciones.

Efectuada la notificación y durante el término de traslado, el demandado puede no contestar la demanda, no oponerse, allanarse a las pretensiones, en estos casos, el juez, vencido el término de traslado emite sentencia ordenando la restitución. Esta decisión también es proferida cuando el demandado contesta la demanda oponiéndose, pero no consigna a órdenes del juzgado los cánones adeudados y que se generen durante el proceso, esto de conformidad con el artículo 384 del CGP.

Si, por el contrario, el demandado se opone durante el término de traslado y consigna los cánones o servicios públicos domiciliarios adeudados más los que se vayan generando durante el proceso, se continua con el trámite dl proceso verbal o verbal sumario según sea el caso, procediendo el juez a fijar fecha para audiencia, terminando dicho proceso en la Sentencia que puede ser a favor del demandado o a favor del demandante ordenando la restitución del bien. 
Una vez se ha emitido la sentencia ordenando la restitución, el juez comisiona a la inspección de policía para celebrar la diligencia de restitución del bien inmueble. Posterior a la sentencia, el demandante cuenta con 30 días para iniciar el ejecutivo a continuación para el cobro de las sumas de dinero ocasionadas.

Dentro de otras particularidades que tiene el proceso de RBIA que se encuentran establecidas en el artículo 384 del CGP (Ley 1564 de 2012) se pueden mencionar la inadmisibilidad de algunos trámites como la demanda de reconvención y la acumulación de procesos, la tramitación como un proceso de única instancia cuando la causal es solamente mora y la posibilidad de solicitar medidas cautelares y de solicitar la restitución provisional previa diligencia de inspección judicial.

\section{Análisis de las estadísticas del Centro de Conciliación de la Corporación Universitaria del Caribe CECAR, en relación a los procesos de RBIA, bajo la modalidad de contrato verbal, durante el año 2017.}

Solicitudes recepcionadas en materia civil en relación e RBIA, durante el año 2017.

Durante el año 2017 se recepcionaron 136 solicitudes en el área civil de las cuales 33 el asunto objeto de conciliación fue restitución de bien inmueble arrendado, correspondiendo al 20\%. En donde además de la RBIA las pretensiones subsidiarias de los fueron:

- Cobro de canon de arrendamiento dejado de cancelar.

- Pago de Servicios Públicos domiciliarios.

- Pago de Mejoras y/o reparaciones locativas.

- Clausula penal. 


\section{Solicitudes en materia civil}

Figura 1. Modalidad de Contratos, solicitudes de audiencias conciliación Centro de Conciliación CECAR 2017.

Fuente de creación: los investigadores en mención, con base al archivo de las estadísticas del año 2017 del Centro de Conciliación de CECAR.

\section{MODALIDAD DE CONTRATO}

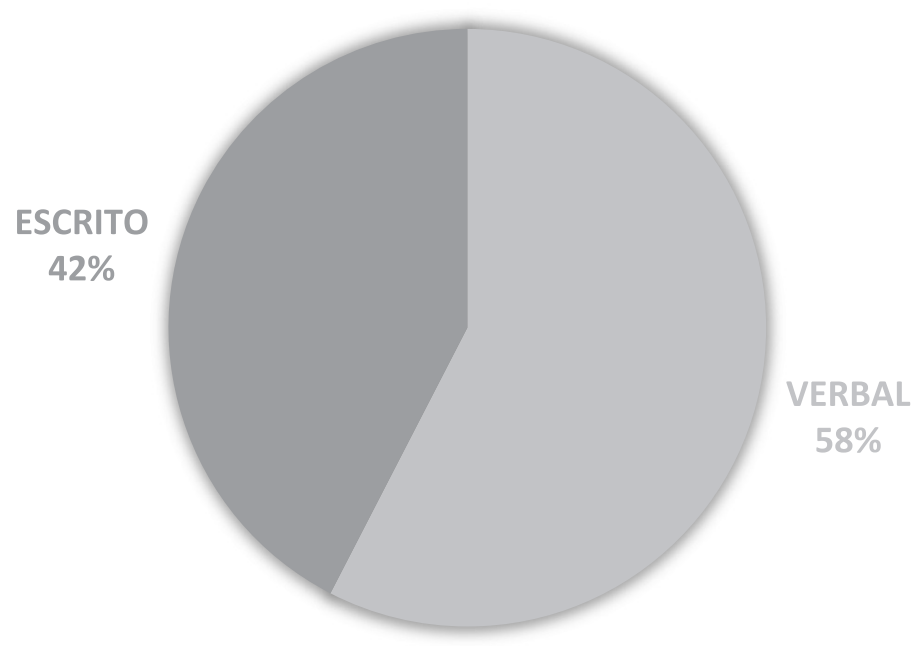

Figura 2. Modalidad de Contratos, solicitudes de audiencias conciliación Centro de Conciliación CECAR 2017.

Fuente de creación: los investigadores en mención, con base al archivo de las estadísticas del año 2017 del Centro de Conciliación de CECAR. 
Las solicitudes de audiencias de conciliación recepcionadas durante el año 2017 en cuanto al tema objeto de estudio se dividen gráficamente de acuerdo a la modalidad del contrato suscrito por las partes, teniendo presente que la ley establece contratos verbales y contratos escritos, produciendo ambos la misma validez jurídica frente a tercero y ante las mismas partes. En esta oportunidad la gráfica 1, describe el porcentaje de contratos celebrados con un total de 33 contratos de arrendamiento, de los cuales 19 son verbales, traducido a un porcentaje del 58\%, y 14 se celebraron de forma escrita, traducido en porcentaje a un $42 \%$ del total de los casos atendidos en dicho asunto.

El método a través del cual se obtuvo la información anteriormente documentada fue mediante del diseño de una ficha dividida de acuerdo a las diferentes modalidades de contratos, resultados arrojados, de registro y el objeto a conciliar.

\section{Resultados de las solicitudes presentadas durante el año 2017, en relación a los procesos de restitución de bien inmueble arrendado RESULTADOS DE SOLICITUDES DE RBIA 2017}

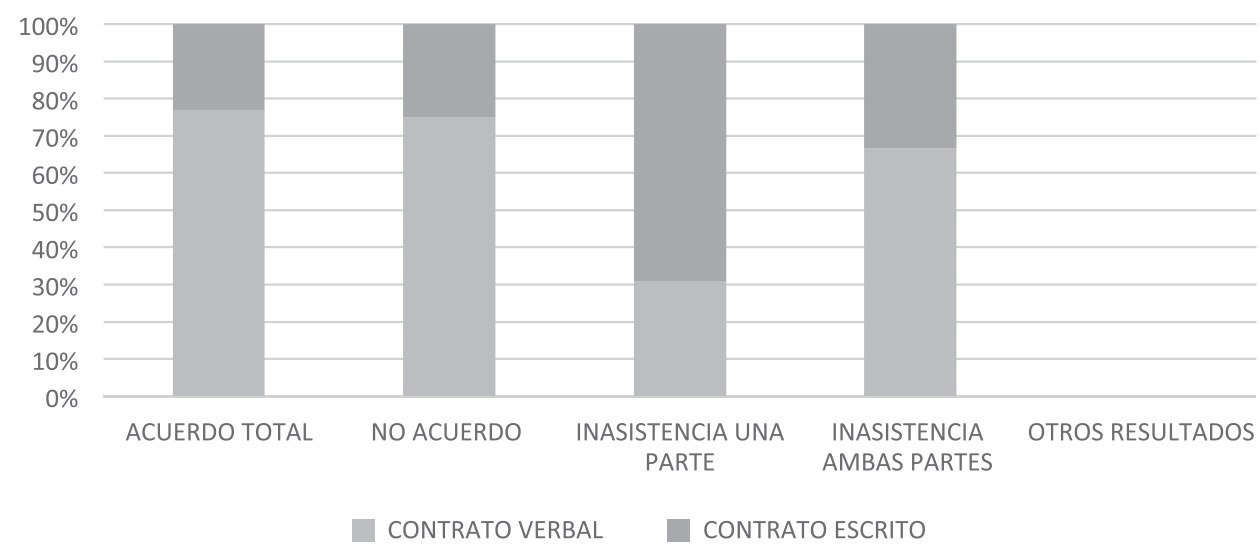

Figura 3. Resultados de solicitudes de audiencias conciliación, recepcionadas en el Centro de Conciliación CECAR, presentadas durante el año 2017, con relación a RBIA, bajo la modalidad de contratos verbales y escritos. 
Efectos de la conciliación extrajudicial en derecho en los procesos de restitución de bien inmueble arrendado originados...

Fuente de creación: los investigadores en mención, con base al archivo de las estadísticas del año 2017 del Centro de Conciliación de CECAR.

De las solicitudes recepcionadas durante el año 2017, donde el objeto de la conciliación era RBIA, de acuerdo al análisis estadístico realizado se traduce en la gráfica 2 y se describen de la siguiente manera:

- Contratos Verbales: Se celebraron en total 19 de los cuales arrojaron como resultado 10 acuerdos, 3 no acuerdo, 4 inasistencia de una parte, y 2 inasistencia de ambas partes. Siendo el mayor resultado los acuerdos totales equivalentes al 53\% de los casos que se presentaron con contratos verbales.

- Contratos Escritos: En cuanto a las audiencias que se celebraron mediante la modalidad de contratos escritos, los resultados fueron 3 acuerdos, 1 no acuerdo, 9 inasistencia de una parte, y 1 inasistencia de ambas partes. A diferencia de los contratos celebrados de manera verbal en estos contratos el mayor resultado fueron las inasistencias de una o de ambas partes, para un total del $71 \%$.

\section{Conclusiones}

Del desarrollo de la investigación, finalmente se ha logrado analizar que la conciliación extrajudicial en derecho como MASC en los procesos de restitución de bien inmueble arrendado celebrados mediante contratos verbales, logran reducir la afluencia de procesos en sede judicial obteniendo así una solución ágil, eficaz y gratuita, partiendo de que los servicios prestados en el Centro de Conciliación de CECAR, son completamente gratuitos para las personas de estratos socioeconómicos 1 y 2 , haciendo énfasis en el asunto susceptible de conciliación abordado en la investigación afirmamos que a través de este mecanismo las personas obtienen un salvavidas jurídico en el entendido de que no tienen un documento escrito que respalde la garantía de su negocio y al celebrar la audiencia de conciliación en un gran porcentaje obtienen satisfacer la pretensión principal que es la restitución del bien inmueble arrendado y las subsidiarias que se presentan como la cancelación de cánones de arrendamiento, pago de servicios públicos domiciliarios, entre otros. Adicionalmente, es de gran importancia dejar por sentado que desde el análisis estadístico elaborado por los investigadores la totalidad de los acuerdos celebrados se cumplieron a cabalidad, obteniendo 
así menos procesos judiciales, y permitiendo el acceso de administración de justicia a la ciudadanía en general.

Como apreciaciones propias de los autores se puede establecer que en ocasiones la conciliación resulta ser más efectiva en aquellos asuntos donde no constituye requisito de procedibilidad que en aquellos en donde así lo establece la ley, toda vez puede entenderse la obligatoriedad de la conciliación como un acuerdo forzado y lejano a la voluntariedad de las partes.

Como recomendaciones por parte del grupo de investigadores se recomienda promover y socializar la figura de la conciliación para evitar litigios dispendiosos, en cuanto a la modalidad de procesos de restitución de inmueble arrendado, así mismo crear cultura de legalidad, en el entendido de que se les recomienden a las personas que realizan negocios jurídicos de arrendamiento lo realicen de manera escrita, para que exista mayor certeza de las condiciones del contrato.

\section{Referencias}

Ardila, N. A. (1991). El contrato de arrendamiento y el proceso de restitucion de inmueble (lanzamiento). Bogotá: Ediciones libreria del profesional.

Constitución Politica de Colombia (7 de julio de 1991).

Corte Cnstitucional Colombiana. Sentencia C - 222 (M.P. María Victoria Calle Correa 17 de abril de 2013).

Corte Suprema de Justicia. Sentencia de Casación del 15 de diciembre de 1948 (15 de diciembre de 1948).

Decreto 1818. Por medio del cual se expide el Estatuto de los mecanismos alternativos de solución de conflictos. (7 de septiembre de 1998).

Decreto 410 De 1971, Código de Comercio Colombiano (27 de marzo de 1971).

Denzin, N. K. (2012). Manual deIinvestigacion Cualitativa. Bogota Colombia .

Diaz, H., \& Contreras, D. E. (2010). La conciliación. Hacia la construccion de un mecanismo efectivo de acceso a la justicia. Bogotá: Universidad Libre. 
Efectos de la conciliación extrajudicial en derecho en los procesos de restitución de bien inmueble arrendado originados...

Estrada, M. (2011). Análisis jurisprudencial de la Conciliación extrajudicial como requisito de procedibilidad en el proceso civil. Cartagena de Indias: Universidad de Cartagena.

Folberg, J., \& Taylor, A. (1997). Mediación, resolucion sin litigio. México: Noriega Editorial.

Instituto SER. (1996). Evolución cuantitativa de la justicia. Bogotá: Revista coyuntura social de Fedesarrollo.

Ley 1564 de 2012, Código General del proceso (15 de julio de 2012).

Ley 270 de 1996. Estatutaria de la administración de justicia (7 de marzo de 1996).

Ley 446 de 1998., Por la cual se adoptan normas del Decr 2651/91, se mod algunas del CPC, se derogan otras de la Ley 23/91 y del Decr 2279/89, se mod y expiden normas del CCA y se dictan disposiciones sobre descongestión, eficiencia y acceso a la justicia (7 de julio de 1998).

Ley 640. Por la cual se modifican normas relativas a la conciliación y se dictan otras disposiciones. (5 de enero de 2001).

Ley 820 de 2003, Por la cual se expide el régimen de arrendamiento de vivienda urbana y se dictan otras disposiciones. (10 de julio de 2003).

Ley 84 de 1873, Código Civil Colombiano. (26 de mayo de 1873).

Mendoza, C. I., \& Sánchez, R. M. (2016). La Conciliación extrajudicial en Derecho: Una alternativa de acceso a la administración de justicia y construcción de paz en la comuna 1 del municipio de Palmira, Valle del cauca. Cali: Pontificia Universidad Javeriana. Obtenido de http://vitela.javerianacali.edu.co/bitstream/handle/11522/8421/ Conciliacion_derecho_alternativa.pdf;jsessionid=D789D1E4F1DA68DECE223C354B0C548D? sequence $=1$

Montoya, J. P. (2015). La responsabilidad civil del intermediario en el arrendamiento de inmuebles. Medellin: Universaidad de Medellín.

Osorio, A. M. (2002). Conciliacion. Mecanismo Alternativo de Solución de Conflictos por excelencia. Bogotá: Pontificia Universidad Javeriana.

Peña, A. M., Polo, C. A., \& Solano, D. X. (s. f.). Conciliación extrajudicial, un análisis a su aplicación práctica desde el punto de vista jurídico. Bogotá: Pontificia Universidad Javeriana.

Peña, O. (2010). Conciliación extrajudicial: teoría y práctica. Lima: APECC. 
Pineda, J. H., \& Resptrepo, S. d. (2014). Contrato de Arrendamiento y Condición Resolutoria: Acerca de la Validez Jurídica y la Aplicación Práctica de la Condición Resolutoria de Pleno Derecho en el Contrato de Arrendamiento de Vivienda Urbana en Colombia. Cartagena de Indias: Universidad de Cartagena.

Real Academia Española. (2001). Diccionario de la lengua española. Madrid. Obtenido de http://www.rae.es/rae.html

Restrepo, B. d. (2011). La conciliación como solución de conflictos. En La conciliación como aplicación alternativa en la solución de conflictos (págs. 165-180). Medellín: Universidad Cooperativa de Colombia.

Semillero de estudios procesales Escuela de Derecho. (2013). Cambios en el proceso civil como reflejo de las necesidades económicas colombianas. Cartagena de Indias: Universidad EAFIT.

Silva, P. T. (2009). Desarrollo de la conciliación a partir de la Constitución de 1991. Panorama(7), 80-86.

Varón, J. C. (Septiembre de 2002). Régimen jurídico de la conciliación en materia civil y comercial. Arbitraje y conciliación, 101-183. 